Check for updates

Cite this: RSC Adv., 2019, 9, 36424

\section{Cyanate ester composites containing surface functionalized BN particles with grafted hyperpolyarylamide exhibiting desirable thermal conductivities and a low dielectric constant $\uparrow$}

\begin{abstract}
Xiuyun Zhang, (D) Fan Wang, Yaping Zhu and Huimin Qi*
Surface functionalized BN particles with grafted hyperbranched polyarylamide (BN-HBP) were prepared and used to improve the thermal conductivity and low dielectric constant of BN-filled cyanate ester resin (BN-HBP/CE) composites. The thermal stability, dielectric properties, thermal conductivity and dynamic mechanical properties of the BN-HBP/CE composites were investigated. The results illustrate that BN$\mathrm{HBP} / \mathrm{CE}$ composites with a load of $32 \mathrm{wt} \%$ exhibit a high glass transition temperature of $283{ }^{\circ} \mathrm{C}$, low dielectric constant of 3.29 at $1 \mathrm{MHz}$, and a desirable thermal conductivity of $0.97 \mathrm{~W} /(\mathrm{m} \cdot \mathrm{K})$. Additionally, these novel materials exhibit a high decomposition temperature of $5 \%$ weight loss at $407{ }^{\circ} \mathrm{C}$ and low curing shrinkage of $-0.64 \%$. When the loading is $38 \mathrm{wt} \%$, the thermal conductivity of BN-HBP/CE composites is $1.27 \mathrm{~W} /(\mathrm{m} \cdot \mathrm{K})$. These findings have significant implications for the preparation of highperformance substrates that meet the requirements for application as printed circuit board substrates.
\end{abstract}

Received 27th August 2019 Accepted 15th October 2019

DOI: 10.1039/c9ra06753a

rsc.li/rsc-advances application requirements of PCBs. In recent years, there has been an increasing interest in cyanate esters (CE) due to their excellent properties. CE resins have a small polarity and avoid depolarization due to their highly symmetric triazine rings, which makes $\mathrm{CE}$ has a low dielectric constant. The stable network of triazine rings render CEs highly heat resistant with a thermal decomposition temperature near $410{ }^{\circ} \mathrm{C}$. Therefore, CE resins possess broad application prospects. However, almost all polymers have low thermal conductivity (around 0.2 ); ${ }^{\mathbf{4 5}}$ it is thus necessary to improve the thermal conductivity of CE resins. At present, the most common method for improving the thermal conductivity of polymers is by adding highly thermally conductive inorganic particles to the polymers. Most studies in the field of CE have only focused on altering the dielectric properties by using fillers; to date, there have been few studies on its thermal conductivity. ${ }^{6-9}$ Electrically insulating thermally conductive fillers is necessary to ensure the dielectric properties of PCBs. For example, the silica-filled cyanate composites prepared by Wooster et al. ${ }^{\mathbf{1 0}}$ exhibited a thermal conductivity of about $0.4 \mathrm{~W} /(\mathrm{m} \cdot \mathrm{K})$ and a dielectric constant of more than 4 with a load of $60 \mathrm{wt} \%$. Commonly used inorganic non-metallic fillers include alumina, silica, boron nitride (BN) and carbon nanotubes. ${ }^{11} \mathrm{BN}$ has high thermal conductivity and low dielectric constant ( $\varepsilon$ is about 4 ) along with excellent thermal stability and electrical insulation. Compared with other commonly used fillers, these excellent properties make $\mathrm{BN}$ a strong candidate for use in a host of broad applications in the PCB field. ${ }^{12,13}$

The filled thermal conductive polymer is composed of a twophase system. The properties of the matrix, the filler and the

$\dagger$ Electronic supplementary information (ESI) available. See DOI: 10.1039/c9ra06753a 
interfacial interaction determine the properties of the composites. ${ }^{\mathbf{1 4}}$ The interface properties have received considerable attention. Extensive research has shown that BN sheets are easy to agglomerate in the polar polymer due to the weak forces between the BN sheets. ${ }^{15}$ A lack of active groups on the surface of $\mathrm{BN}$ causes poor compatibility between $\mathrm{BN}$ and polymers. The weak interfacial adhesion is accompanied by interface defects, which can cause interface phonon scattering which manifests as an interfacial thermal resistance. ${ }^{\mathbf{1 6}, 17}$ Thus far, many scholars have studied the properties of BN-filled composites. ${ }^{12,18}$ Huang and Ishida ${ }^{\mathbf{1 3}}$ studied the effects of BN surface modification on the polymerization and dynamic mechanical properties of benzooxazinyl composites. Huang et $a .^{\mathbf{4}}$ prepared epoxy composites via surface treatment of $\mathrm{BN}$. With the loading of $30 \mathrm{wt} \%$, the thermal conductivity of the composite is about $0.8 \mathrm{~W} /(\mathrm{m} \cdot \mathrm{K})$, the dielectric constant is greater than 4 , and the dielectric loss is greater than 0.02 . Wu and Kessler ${ }^{19}$ used polydopamine modified BN to prepare the composites of bisphenol E cyanate resin with a thermal conductivity of $0.55 \mathrm{~W} /(\mathrm{m} \cdot \mathrm{K})$ and a dielectric constant of more than 3.7 when the BN content was $28 \mathrm{wt} \%$. In addition, the surface modification reduces the thermal conductivity of the composites to about $0.5 \mathrm{~W} /(\mathrm{m} \cdot \mathrm{K})$. There has been no detailed investigation of the impact of $\mathrm{BN}$ on the dielectric properties of cyanate ester.

Although the surface treatment of $\mathrm{BN}$ has been widely implemented to improve the thermal conductivity for CEs, most studies in the research literature directly use a method of grafting a silane coupling agent on the surface of BN. One of the main problems with this method is that due to the inert surface of $\mathrm{BN}$, a significant increase in thermal conductivity is not seen in the resulting composites. Most studies concerning PCB have only focused on the thermal conductivity of composites. The second problem in the existing research is that the addition of $\mathrm{BN}$ increases the dielectric constant of the composites, which affects the transmission speed of signal. In addition, studies have shown that $\mathrm{BN}$ will precipitate during curing of the resin; this also reduces the dielectric properties of the composites due to a large increase in the viscosity of the resin.

The main challenge faced by today's researchers is to find an effective surface modification that maximizes the advantage of $\mathrm{BN}$ (high thermal conductivity) while improving dielectric properties of the composites. In this study, surface functionalized BN particles (BN-HBP) were prepared by grafting hyperbranched polyarylamide onto the surface of $\mathrm{BN}$ particles (herein referred to as BN-HBP). The surface rigidity of the BN-HBP polyarylamide backbone could play a better role in heat transfer, minimizing phonon scattering at the interface. ${ }^{20-22}$ Therefore the thermal conductivity could be improved and dielectric constant could be reduced. In addition, the surface modification of $\mathrm{BN}$ in the present work reduces the surface energy of the particles and reduces the processing viscosity of the composite. In the process, the in situ polymerization method promotes uniform dispersion of BN-HBP and slows down the sedimentation of BN during the curing process. This paper analyses the impact of filler content and surface functionalization on the dielectric and thermal properties of the composites, as well as its effect on the curing behavior and thermal stability of the composites.

\section{Experimental}

\subsection{Materials}

Dicyanate of bisphenol A (CE): melting point $80-81{ }^{\circ} \mathrm{C}$, purity 99.5\%, was made in our laboratory. 3,5-Diaminobenzoic acid and triphenyl phosphite were purchased from Meryer (Shanghai) Chemical Technology Co., Ltd., Shanghai, China. Pyridine, $N$-methyl pyrrolidone, pyridine, ethanol and $N, N$ dimethylformamide were purchased from Titan Technology Co., Ltd., Shanghai, China. Methanol and 3-aminopropyl triethoxy-silane (KH550) were purchased from Shanghai Aladdin Bio-Chem Technology Co., Ltd., Shanghai, China. BN particles were purchased from Yingkou Tianyuan Chemical Research Institute Co., Ltd., Shanghai, China. The average particle size was $10 \mu \mathrm{m}$.

\subsection{Preparation of surface functionalized $\mathrm{BN}$ particles}

Surface functionalized BN particles were prepared with three steps: (1) weakening of B-N bonds; (2) treatment with a silane coupling agent; and (3) hyperbranched grafting. The prepared process of BN surface functionalization is shown in Fig. 1.

$\mathrm{BN}$ particles were introduced into a solution of concentrated sulfuric acid and concentrated nitric acid (volume ratio $1: 3$ ). The mixture was stirred at $80{ }^{\circ} \mathrm{C}$ for $80 \mathrm{~h}$. Next, the BN particles were rinsed with water until the $\mathrm{pH}$ was neutral. The BN particles were then dried for $24 \mathrm{~h}$ at $65^{\circ} \mathrm{C}$ under vacuum. Finally, the acidified $\mathrm{BN}$ particles were obtained. The acid-treated BN particles are henceforth referred to as BN-AC.

$\mathrm{KH}-550$ (BN weight of $2.4 \%$ ) was added to $95 \%$ ethanol solution and stirred for $10 \mathrm{~min}$. The BN-AC were then introduced into the solution and stirred at $60{ }^{\circ} \mathrm{C}$ for $7 \mathrm{~h}$. After filtering the mixture, the particles were dried for $10 \mathrm{~h}$ at $60{ }^{\circ} \mathrm{C}$ under vacuum to obtain treated BN particles. KH550 (3-aminopropyl triethoxysilane) treated BN particles are referred to as BN-APS.

3,5-Diaminobenzoic acid was dissolved in $50 \mathrm{~mL} \mathrm{~N}$-methyl pyrrolidone (NMP), then $7.5 \mathrm{~mL}$ pyridine and $9 \mathrm{~g}$ triphenyl phosphite were separately added to the solution. Three grams of BN-APS particles were then discharged into the system and the reaction was carried out for $4 \mathrm{~h}$ at $100{ }^{\circ} \mathrm{C}$ under nitrogen conditions. After cooling the BN particles to room temperature, they were washed three times with methanol, $N, N$-dimethylformamide and again with methanol, respectively. Finally, the BN particles were dried in a vacuum for $12 \mathrm{~h}$ at $90{ }^{\circ} \mathrm{C}$. The obtained surface functionalized $\mathrm{BN}$ particles are referred to as BN-HBP.

\subsection{Preparation of $\mathrm{BN}-\mathrm{HBP} / \mathrm{CE}$ composites}

The BN filled CE resins were obtained via molten blending and prepolymerization of surface functionalized BN particles and $\mathrm{CE}$ resins. CE resins ( $45 \mathrm{~g}$ ) was heated at $90{ }^{\circ} \mathrm{C}$ to a molten state in a flask. Next, a given weight of BN-HBP particles were gradually added to the resin and stirred for $1.5 \mathrm{~h}$ until the BN particles were completely dispersed in the resin. The resin was prepolymerized while sequentially stirring for $2 \mathrm{~h}$ at $100{ }^{\circ} \mathrm{C}$, for $1 \mathrm{~h}$ at $120^{\circ} \mathrm{C}$, and for $2 \mathrm{~h}$ at $130{ }^{\circ} \mathrm{C}$. A light yellow opaque viscous $\mathrm{BN}$ filled $\mathrm{CE}$ resin was thus obtained. 

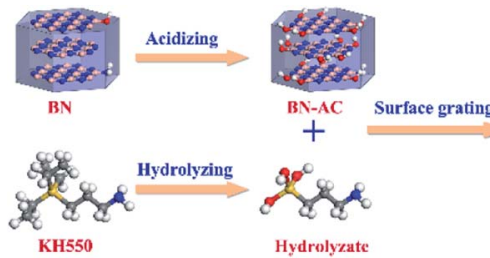

$+\quad$

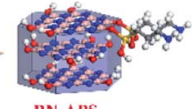

KH550
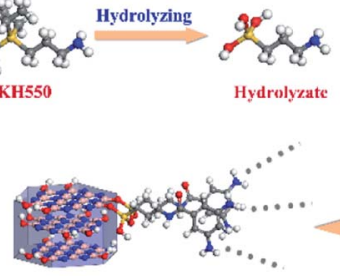

BN-HBP

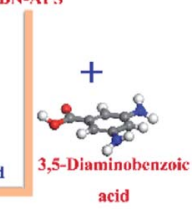

Fig. 1 Process of surface functionalization of BN.

The fluidized BN-filled CE resins were cast in a mold preheated to $110{ }^{\circ} \mathrm{C}$ in an oven. They were cured and post cured in the following sequence: $2 \mathrm{~h}$ at $140{ }^{\circ} \mathrm{C}, 2 \mathrm{~h}$ at $160{ }^{\circ} \mathrm{C}, 2 \mathrm{~h}$ at $180^{\circ} \mathrm{C}, 2 \mathrm{~h}$ at $210^{\circ} \mathrm{C}$, and $2 \mathrm{~h}$ at $230^{\circ} \mathrm{C}$. Yellow opaque BN-HBP/ $\mathrm{CE}$ composites were thus obtained.

\subsection{Characterizations}

Fourier-transform infrared (FTIR) spectra were recorded on a Nicolet 6700 spectrometer (Thermo Fisher) in the range of $4000-400 \mathrm{~cm}^{-1}$ at resolution of $0.09 \mathrm{~cm}^{-1}$.

The tested samples were made by grounding $\mathrm{BN}$ with $\mathrm{KBr}$ and then compressing the mixture into pellets. An X-ray photoelectron spectrometer (XPS; Thermo Fisher, USA) was employed to perform surface characterization of BN particles. Differential scanning calorimetric (DSC) analysis was obtained using a PerkinElmer Diamond DSC with a 7-10 $\mathrm{mg}$ of sample at a scanning rate of $10{ }^{\circ} \mathrm{C} \min ^{-1}$ from $30{ }^{\circ} \mathrm{C}$ to $35{ }^{\circ} \mathrm{C}$ under nitrogen flow. A scanning electron microscope (SEM, Hitachi S4800) was employed to observe the morphologies of the fractured surfaces of the composites. Thermal gravimetric analysis was performed on a TA instrument SDT Q600 by using 8-15 mg samples at the heating rate of $5{ }^{\circ} \mathrm{C} \mathrm{min}^{-1}$ from $25^{\circ} \mathrm{C}$ to $1000{ }^{\circ} \mathrm{C}$ under nitrogen flow $\left(70 \mathrm{~mL} \mathrm{~min}^{-1}\right)$. Dynamic mechanical analysis (DMA) using samples with dimensions of $45 \times 8.5 \times$ $2.5 \mathrm{~mm}$ was performed on a Mettler-Toledo (Switzerland) in a three-point-blending mode with the following conditions: a temperature range of $50-300{ }^{\circ} \mathrm{C}$, a heating rate of $5{ }^{\circ} \mathrm{C} \mathrm{min}{ }^{-1}$ from $50{ }^{\circ} \mathrm{C}$ to $300{ }^{\circ} \mathrm{C}$, an amplitude of $15 \mu \mathrm{m}$, and a frequency of $1 \mathrm{~Hz}$. Dielectric properties of the samples $(\Phi 30 \times 1.1 \mathrm{~mm})$ were measured on a broadband dielectric spectrometer (Novocontrol Concept 40, Germany) at room temperature over a frequency range from 1 to $10^{7} \mathrm{~Hz}$.

The curing shrinkage of the samples' resin was obtained from testing the density before curing and after curing by a densitometer (METTLER TOLEDO ME204E). The calculation formula for shrinkage is as follows:

$$
V_{\mathrm{s}}=\frac{\rho_{1}-\rho_{2}}{\rho_{1}} \times 100 \%
$$

$V_{\mathrm{s}}$ : sample volume shrinkage, $\% ; \rho_{1}$ : density of the cured resin, $\mathrm{g} \mathrm{cm}^{-3} ; \rho_{2}$ : density of the uncured resin, $\mathrm{g} \mathrm{cm}^{-3}$.

Thermal conductivity measurements of the samples $(\Phi 30 \times$ $1.5 \pm 0.5 \mathrm{~mm}$ ) were measured using a Netzsch LFA447 according to the ASTM E1461 at room temperature. The thermal conductivity is calculated by the product of thermal diffusivity and the specific heat and density, where the density was measured by volume exclusion.

\section{Results and discussion}

\subsection{Preparation and characterization of surface functionalized $\mathrm{BN}$ particles}

Surface modification of fillers has been demonstrated to be an efficient method for improving the interface properties of inorganic fillers and resins. However, for BN particles, surface treatment is difficult due to its chemical inertness. Herein, the $\mathrm{BN}$ particles were treated with strong acid, silane coupling agent KH550 and grafting polymerization of 3,5-diaminobenzoic acid. The chemical reaction process of $\mathrm{BN}$ surface functionalization is shown in Fig. 1. Acid treatment effectively weakens B-N bonds; the $\mathrm{B}$ atom at the edge of $\mathrm{BN}$ is activated. $\mathrm{An}-\mathrm{OH}$ group can be bonded to the electron-deficient $\mathrm{B}$ atom, and then, the functional group can be introduced on the BN surface. The coupling agent can be hydrolyzed into $\mathrm{NH}_{2}\left(\mathrm{CH}_{2}\right)_{3} \mathrm{SiOH}$, forming an oligomeric structure via the dehydration condensation reaction. Hydrogen bonds can be formed between the oligomer structure and the $\mathrm{OH}$ groups on the surface of the BN-AC, which can further form a partial covalent bond by a dehydration reaction. Finally, the surface of the BN-AC is covered by the silane coupling agent. BN-APS is a white to yellowish powder. Polyarylamide can be successful grafted by the amino group on the surface of BN-APS, further improving the interfacial compatibility between $\mathrm{BN}$ and $\mathrm{CE}$. More importantly, the rigidity polyarylamide backbone plays a strong role in heat transfer.

The chemical structure and morphology of the as-prepared surface functionalized BN particles were characterized by FTIR, TGA, XPS and SEM. Fig. 2 shows the FTIR spectrum of BN raw materials, BN-APS and BN-HBP. All of the FT-IR spectra show two distinct absorption bands at $1370 \mathrm{~cm}^{-1}$ and $817 \mathrm{~cm}^{-1}$ which represent $\mathrm{B}-\mathrm{N}$ stretching vibrations and $\mathrm{B}-\mathrm{N}-\mathrm{B}$ bending vibrations, respectively. ${ }^{23}$ In the FTIR spectrum of BN-APS, the $\mathrm{C}-\mathrm{H}$ band is found at $2926 \mathrm{~cm}^{-1}$ and $2852 \mathrm{~cm}^{-1} \cdot{ }^{24}$ The $\mathrm{Si}-\mathrm{O}$

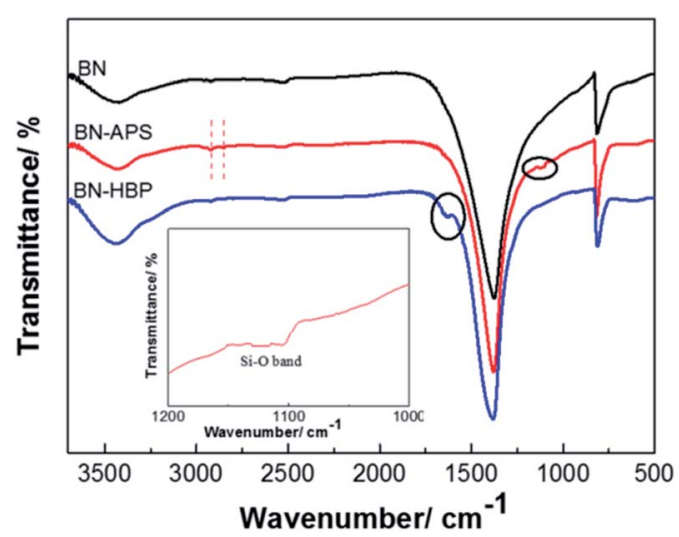

Fig. 2 FTIR spectra of BN, BN-APS and BN-HBP. 
band is found at $1100 \mathrm{~cm}^{-1}$, which is due to the dehydration condensation between $\mathrm{OH}$ groups on the surface of $\mathrm{BN}-\mathrm{AC}$ and the $\mathrm{OH}$ groups produced by the hydrolysis of the coupling agent. ${ }^{25}$ New peaks are observed at $1626 \mathrm{~cm}^{-1}$ in the FT-IR spectrum of BN-HBP as a result of the reaction between amino groups on the surface of BN-APS and benzoic acid monomers. ${ }^{26}$ Compared with the raw $\mathrm{BN}$, the appearance of the new peaks in the FTIR spectrum of BN-APS and BN-HBP clearly demonstrates that the BN surface has been successfully functionalized by the silane coupling agent and hyperbranched polymer.

The TGA curves of BN raw materials, BN-APS and BN-HBP were shown in Fig. 3. BN-HBP exhibits obvious weight loss under about $400{ }^{\circ} \mathrm{C}$. At $1000^{\circ} \mathrm{C}$, the mass residue of the $\mathrm{BN}-\mathrm{HBP}$ samples is $98.9 \%$ compared with the BN raw materials (99.9\%). Successful grafting of hyperbranched polyarylamide on the BN surface can be further illustrated.

Fig. 4 shows the XRD patterns of $\mathrm{BN}$ and $\mathrm{BN}-\mathrm{HBP}$ particles. The diffraction peak shape and position of BN and BN-HBP are completely the same. The obvious peak observed are assigned to the diffraction peaks of $\mathrm{BN}$ corresponding to the crystal faces of (002), (100), (102), (004) and (110). XRD results indicates that the surface functionalization of $\mathrm{BN}$ does not change its basic characteristics.

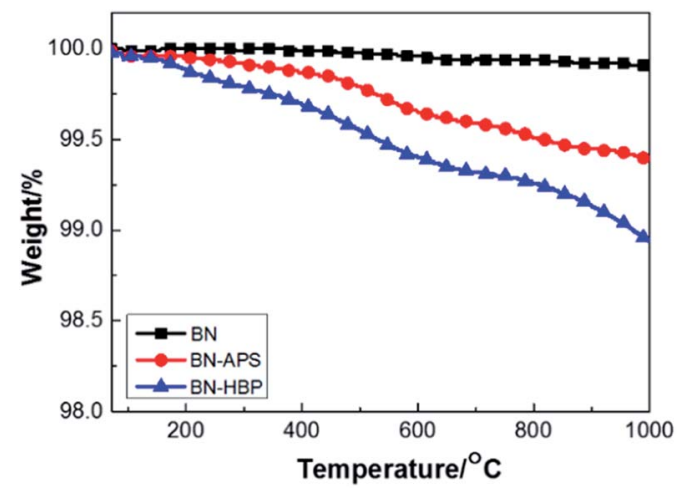

Fig. 3 TGA curves of BN, BN-APS and BN-HBP.

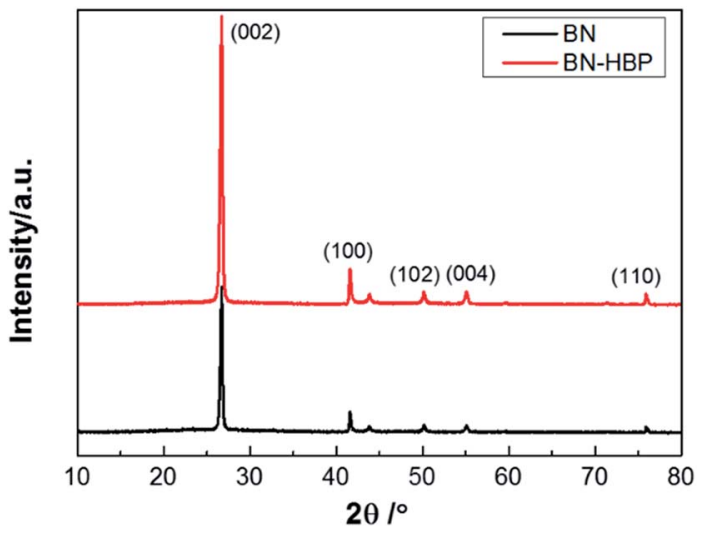

Fig. 4 XRD patterns of $\mathrm{BN}$ and $\mathrm{BN}-\mathrm{HBP}$.
To confirm the above discussion, XPS of BN-HBP was performed and is shown in Fig. 5. The ratio between the concentrations of each element is summarized in the Table 1. In addition to $\mathrm{B} 1 \mathrm{~s}$ and $\mathrm{N} 1 \mathrm{~s}, \mathrm{C}$ 1s can be clearly observed in the spectrum of BN-HBP. It can be seen from Fig. 5(b), which shows the core level spectrum of $\mathrm{N} 1 \mathrm{~s}$. The $\mathrm{N} 1 \mathrm{~s}$ spectrum of $\mathrm{BN}-\mathrm{HBP}$ is divided into two independent peaks: $\mathrm{B}-\mathrm{N}$ bonds are represented at $398 \mathrm{eV}$ and $\mathrm{N}-\mathrm{H}$ bonds are represented at $401.9 \mathrm{eV} .^{27,28}$ The presence of $\mathrm{C}$ and $\mathrm{O}$ elements also demonstrates the success of surface functionalization.

Table 2 shows the results of elemental analysis. The data show that the $\mathrm{N}$ content of $\mathrm{BN}-\mathrm{HBP}$ particles is relatively decreased and the content of $\mathrm{C}$ is increased.

In addition to the above characterization, morphological studies can clearly indicate the difference between $\mathrm{BN}$ and $\mathrm{BN}$ HBP, as shown in Fig. 6. It can be seen that BN is a multi-layered $\mathrm{BN}$ sheet laminated in the shape of a hexagonal sheet. BN-HBP shows an uneven surface and increased edge roughness compared with the smoother raw BN. The rougher BN-HBP helps to disperse $\mathrm{BN}$ in the matrix and improve the interfacial properties of the composites.
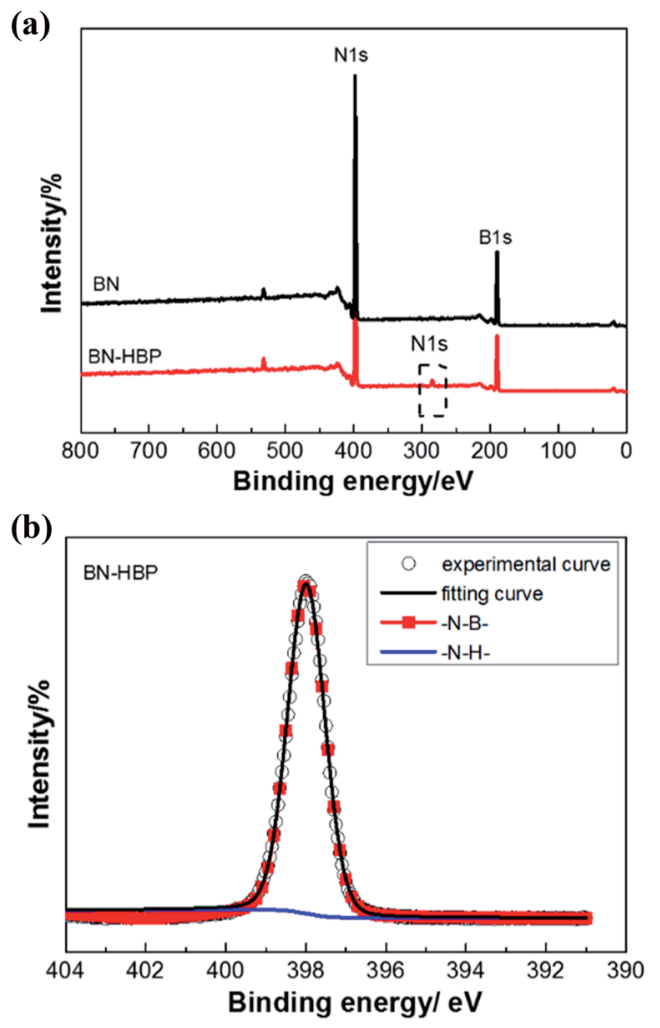

Fig. 5 (a) XPS spectra of $\mathrm{BN}$ and $\mathrm{BN}-\mathrm{HBP}$, (b) the core level spectrum of $\mathrm{N} 1 \mathrm{~s}$.

Table 1 The concentration of BN-HBP

\begin{tabular}{llllll}
\hline Elemental & B 1s & N 1s & C 1s & O 1s & Si 2p \\
Chemical composition/\% & 52.5 & 42.1 & 3.2 & 2.1 & 0.2
\end{tabular}


Table 2 Elemental analysis of BN-HBP

\begin{tabular}{lcc}
\hline Sample & N/\% & C/\% \\
\hline BN & 56.6 & 0.9 \\
BN-HBP & 41.5 & 4.2
\end{tabular}

\subsection{Preparation and characterization of surface functionalized $\mathrm{BN}$ particles}

The BN-HBP/CE resins were obtained via molten blending and prepolymerizing surface functionalized $\mathrm{BN}$ particles and $\mathrm{CE}$ resin. To understand the effect of the BN-HBP filler on the BN$\mathrm{HBP} / \mathrm{CE}$ resins and $\mathrm{BN}-\mathrm{HBP} / \mathrm{CE}$ composites, $\mathrm{BN}-\mathrm{HBP} / \mathrm{CE}$ resins with different loading contents of $\mathrm{BN}-\mathrm{HBP}$ particles were prepared, as shown in Table 3. All BN-HBP/CE resin samples were homogeneous and stratified. As the content of BN-HBP increased, the viscosity of the $\mathrm{BN}-\mathrm{HBP} / \mathrm{CE}$ resin increased, and the fluidity gradually decreased. When the content of BNHBP was less than $35 \%$, the $\mathrm{BN}-\mathrm{HBP} / \mathrm{CE}$ resin had good fluidity and exhibited good processing performance.

The cure behavior and curing shrinkage of the BN-HBP/CE resins were exanimated. The DSC of the $\mathrm{BN}-\mathrm{HBP} / \mathrm{CE}$ resins are shown in Fig. 7. All $\mathrm{BN}-\mathrm{HBP} / \mathrm{CE}$ resins exhibit a single

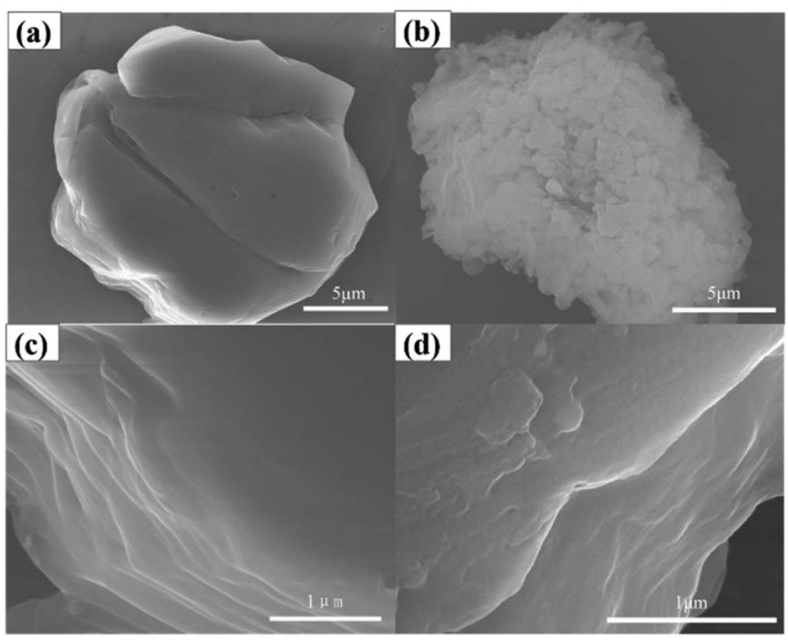

Fig. 6 SEM images of $(a-c) B N$ raw, $(b-d) B N-H B P$. exothermic peak, which is characteristic of the CE resin curing process. The peak temperature of neat $\mathrm{CE}$ resin is $243{ }^{\circ} \mathrm{C}$; the $\mathrm{BN}-\mathrm{HBP} / \mathrm{CE}$ resin showed a higher value for the exothermic peak temperature, from $267^{\circ} \mathrm{C}$ to $277^{\circ} \mathrm{C}$. This indicates that the $\mathrm{CE}$ molecular chain on the BN-HBP surface requires more energy to participate in the curing reaction. Thus, the polymerization of the CE molecular chain on the surface of BN-HBP is hindered..$^{29}$ One possible explanation involves molecular mobility restrictions occurring at the BN-HBP surface. The grafted polymers are intertwined with the CE molecular chain, resulting in the need for more supplied energy to increase the mobility of functional groups such that they are in close enough proximity to one another to react. ${ }^{30}$

The curing shrinkage of $\mathrm{BN}-\mathrm{HBP} / \mathrm{CE}$ resins were investigated, as shown in Table 3. The curing shrinkage of the neat CE resin is $2.11 \%$. The value is $-0.64 \%$ with $\mathrm{BN}-\mathrm{HBP}$ particle loading of $32 \mathrm{wt} \%$. In comparison, the shrinkage of BN-HBP35/ CE composite is $-0.42 \%$, thus there is a great improvement of the dimensional stability in the composites.

\subsection{Structure and properties of $\mathrm{BN}-\mathrm{HBP} / \mathrm{CE}$ composites}

(1) Morphological structure. The fractured surfaces of $\mathrm{BN}$ HBP/CE composites were examined by using SEM to measure the dispersion state of $\mathrm{BN}-\mathrm{HBP}$ particles with $\mathrm{CE}$ resin, as shown in Fig. 8(a-c). In order to comparatively study the dispersion state of BN-HBP particles with $\mathrm{CE}$ resin and interfacial performance, a BN32/CE composite was prepared, as shown in Fig. 8(d).

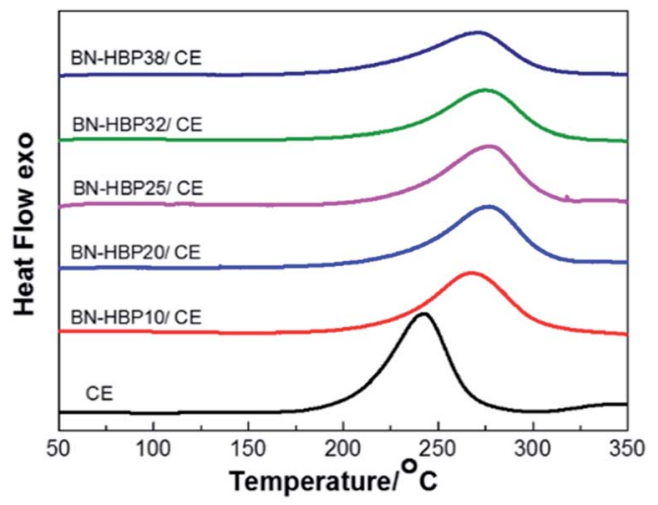

Fig. 7 DSC thermograms of $\mathrm{BN}-\mathrm{HBP} / \mathrm{CE}$ resin with various ratios.

Table 3 Composition formula and curing shrinkage of BN-HBP/CE resins

\begin{tabular}{|c|c|c|c|c|c|c|}
\hline Sample & $\mathrm{CE}(\%)$ & BN-HBP (\%) & Samples state $/ 110^{\circ} \mathrm{C}$ & $\begin{array}{l}\text { Density }\left(\mathrm{g} \mathrm{mL}^{-1}\right) \\
\text { (before cured) }\end{array}$ & $\begin{array}{l}\text { Density }\left(\mathrm{g} \mathrm{mL}^{-1}\right) \\
\text { (after cured) }\end{array}$ & $\begin{array}{l}\text { Shrinkage } \\
(\%)\end{array}$ \\
\hline $\mathrm{CE}$ & 100 & 0 & Excellent fluidity & 1.208 & 1.234 & 2.11 \\
\hline BN-HBP10/CE & 90 & 10 & Great fluidity & - & - & - \\
\hline BN-HBP20/CE & 80 & 20 & Good fluidity & - & - & - \\
\hline BN-HBP25/CE & 75 & 25 & General fluidity & 1.363 & 1.338 & -1.87 \\
\hline BN-HBP32/CE & 68 & 32 & General fluidity & 1.423 & 1.414 & -0.64 \\
\hline BN-HBP35/CE & 65 & 35 & Less fluidity & 1.444 & 1.448 & -0.42 \\
\hline BN-HBP38/CE & 62 & 38 & Poor fluidity & 1.455 & 1.448 & -0.48 \\
\hline
\end{tabular}



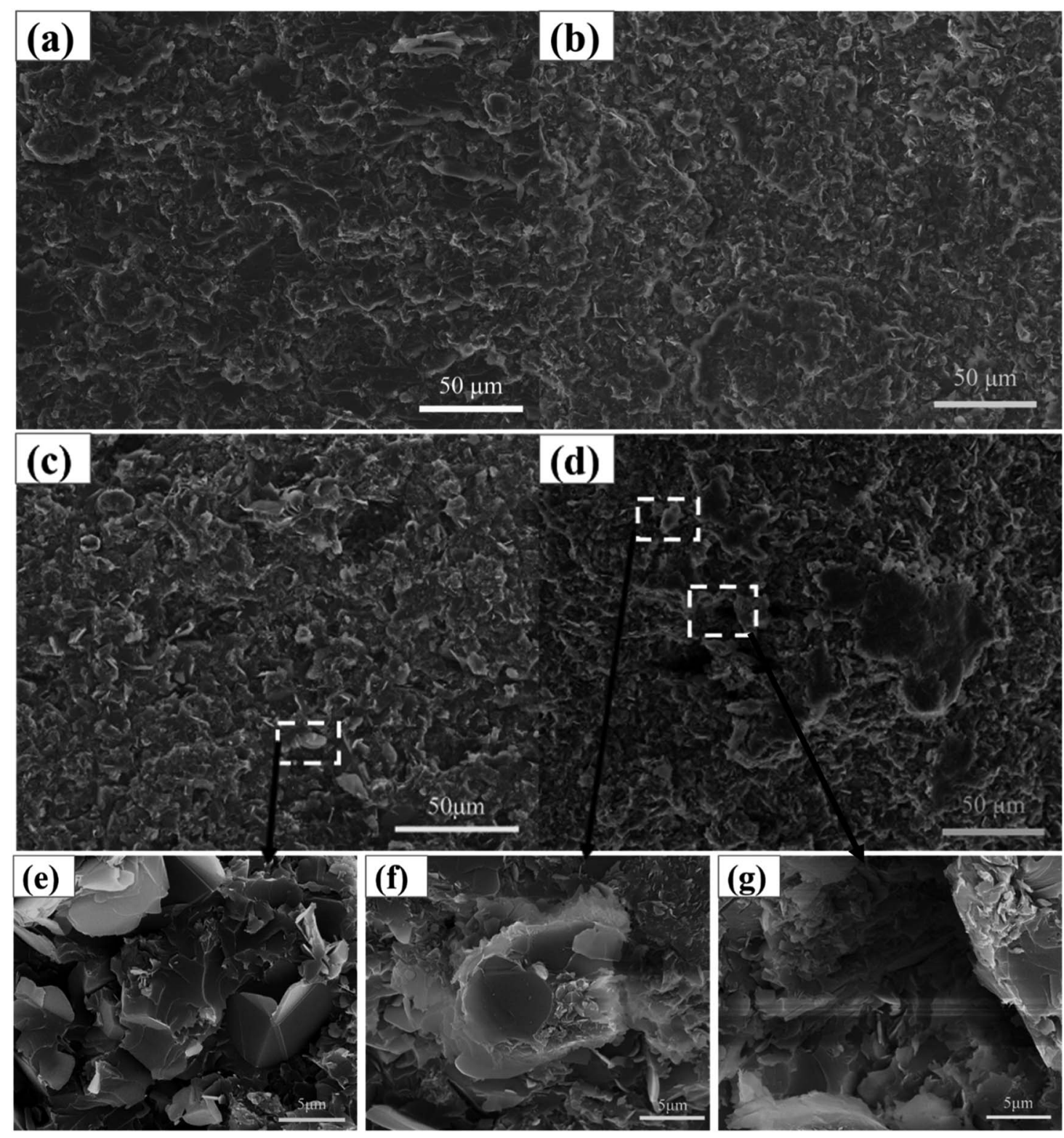

Fig. 8 SEM images of the fracture surfaces of (a) BN-HBP15/CE, (b) BN-HBP25/CE, (c) BN-HBP32/CE, (d) BN32/CE, (e) BN-HBP32/CE, (f and g) BN32/CE.

When the content of $\mathrm{BN}$ is $32 \mathrm{wt} \%$, the number of holes and bare $\mathrm{BN}$ on the fracture surface of the BN32/CE composites increases significantly. When the BN32/CE composite was observed at higher magnification, no resin encapsulation was seen in the agglomerated $\mathrm{BN}$, it was less compatible with the matrix (Fig. 8f), and the surface of the pores were smooth. These features indicate poor interfacial adhesion of the composite (Fig. 8g). In contrast, surface functionalization of BN improves its dispersion in CE (Fig. 8a-c). When the BN-HBP content was increased from $15 \mathrm{wt} \%$ to $32 \mathrm{wt} \%$, the cross-section of composites has almost no holes or cracks. When the BN-HBP32/ $\mathrm{CE}$ composite was observed at a higher magnification, it can be seen that the BN-HBP is embedded in the CE matrix; the surface of the filler is well wrapped with the resin (Fig. 8e). This further proves that the surface functionalization effectively improves the dispersion of $\mathrm{BN}$ and reduces the defects of the composites, resulting in enhanced interfacial compatibility and interfacial adhesion. These findings confirm our conclusion.

(2) Dielectric properties. The dielectric constant and loss of $\mathrm{BN}-\mathrm{HBP} / \mathrm{CE}$ composite dependence on frequency are shown in Fig. 9, dielectric constant of the $\mathrm{BN}-\mathrm{HBP} / \mathrm{CE}$ composites at different frequencies is listed in Table S2. $\dagger$ Dielectric properties of the samples were measured at room temperature. The dielectric properties of $\mathrm{BN}-\mathrm{HBP} / \mathrm{CE}$ composites are related to dipole polarization associated with the $\mathrm{CE}$ resin and $\mathrm{BN}-\mathrm{HBP}$ fillers as well as with interfacial polarization. ${ }^{31-33}$ Since $\mathrm{BN}$ has a dielectric constant $(\varepsilon)$ of 4.9 larger than that of neat $\mathrm{CE}$ resin, the $\varepsilon$ of $\mathrm{BN}-\mathrm{HBP} / \mathrm{CE}$ composites increases with increasing $\mathrm{BN}$ HBP content. The increase in BN-HBP content leads to an increase in the micro-interface area of the composites. This 

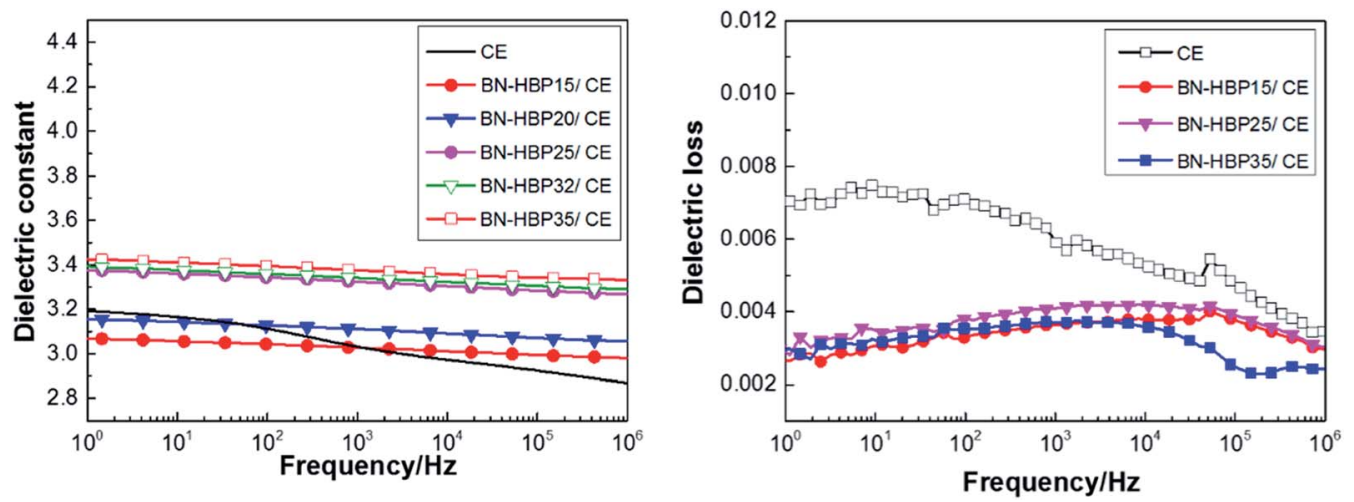

Fig. 9 Dielectric properties vs. frequency of BN-HBP/CE composites with different content fillers.

enhances the space-charge polarization and ultimately leads to an increase in $\varepsilon^{19,34}$ The dielectric loss of the BN-HBP/CE composites decreases with increasing BN-HBP content. This is attributed to the fact that a decrease in molecular chain mobility makes it difficult for $\mathrm{CE}$ molecules to polarize. ${ }^{35}$ In addition, as the viscosity of the BN-HBP/CE resin increases with increasing filler content, interfacial polarization becomes difficult, which results in reduced dielectric loss at high frequencies. ${ }^{36}$

It can be observed from Fig. 9(a and b) that BN-HBP/CE composites show a low dielectric constant and stable dielectric loss. At a frequency of $1 \mathrm{MHz}, \mathrm{BN}-\mathrm{HBP} / \mathrm{CE}$ composites with a load of $32 \mathrm{wt} \%$ exhibit a lower $\varepsilon$ value (3.29). This is mainly because the BN-HBP surface is coated with hyperbranched polyarylamide, which strengthens the organic-inorganic interfacial adhesion and reduces the interfacial polarization. ${ }^{14,37}$ Moreover, surface functionalization allows BN-HBP to be uniformly dispersed amongst the CE matrix, thus reducing the sedimentation of BN during the curing process. This offsets the adverse effect on the dielectric properties resulting from the introduction of $\mathrm{BN}-\mathrm{HBP} .^{38}$ We concluded that the surface functionalization of $\mathrm{BN}$ particles could improve the dielectric properties of BN-HBP/CE composites.

(3) Thermal conductivity. The thermal physical properties of BN-HBP/CE composites are summarized in Table 4. It is known that the thermal conductivity of composites depends on the intrinsic thermal conductivity of the matrix, the filler, and the loading content of the filler. ${ }^{14,39}$ As shown in Table 4 , the $\lambda$ of BN$\mathrm{HBP} / \mathrm{CE}$ composites are enhanced as the increasing filler content is increased. The interaction of the filler with the matrix plays an important role because incompatibility at the interface leads to a resistance of heat conduction..$^{40}$ Studies have shown that the thermal conductivity of the air in the hole is extremely low, only $0.0024 \mathrm{~W} /(\mathrm{m} \cdot \mathrm{K}) \cdot{ }^{41}$ Chemical reactions between the functional groups on the surface of BN-HBP and CE improve the interfacial compatibility during the curing of $\mathrm{CE}$, consequently reducing defects at the interface.

Compared with the pure CE resin, the $\lambda$ is $0.197 \mathrm{~W} /(\mathrm{m} \cdot \mathrm{K})$, the value of $\mathrm{BN}-\mathrm{HBP} 38 / \mathrm{CE}$ composite is $1.27 \mathrm{~W} /(\mathrm{m} \cdot \mathrm{K})$, and the thermal conductivity increases by $545 \%$. It was found that the presence of BN-HBP contributed to the thermal conductivity of the composites. According to covalent bonding theory, the hyperbranched polyaramid polymer on the surface of BN-HBP plays a bridging role between $\mathrm{BN}$ and $\mathrm{CE}^{42}$

This increases the chemical cross-linking point in the threedimensional network and reduces the thermal resistance of the interface. Meanwhile, the grafted polymer on the surface of BNHBP also reduces the mismatch of modulus between BN-HBP and the CE matrix. ${ }^{43}$ In addition, dispersion of the filler in the CE matrix may affect the thermal conductivity of the composites. ${ }^{4-46}$ As shown in Fig. 8, BN-HBP clearly exhibits more uniform dispersion, increased wettability and good interfacial compatibility. ${ }^{3,40}$

(4) Thermal stability. To investigate the thermal stability of $\mathrm{BN}-\mathrm{HBP} / \mathrm{CE}$ composites with various content of BN-HBP, TGA of the BN-HBP/CE composites was performed under nitrogen flow. The TG curves and corresponding derivative curves are shown in Fig. 10. It can be seen that all of the BN-HBP/CE composites possess outstanding thermal stability. The thermal decomposition temperature $\left(\mathrm{Td}_{5}\right.$, temperature at $5 \%$ weight loss) of neat

Table 4 Thermal conductivity, thermal diffusivity and specific heat of BN-HBP/CE composites

\begin{tabular}{llll}
\hline Sample & Thermal conductivity/W/(m·K) & Thermal diffusivity $/\left(\mathrm{mm}^{2} \mathrm{~s}^{-1}\right)$ & Specific heat $/\left(\mathrm{J} \mathrm{g}^{-1} \mathrm{~K}^{-1}\right)$ \\
\hline CE & 0.197 & 0.134 & 1.218 \\
BN-HBP15/CE & 0.385 & 0.292 & 1.024 \\
BN-HBP20/CE & 0.587 & 0.399 & 1.111 \\
BN-HBP25/CE & 0.689 & 0.533 & 0.967 \\
BN-HBP32/CE & 0.968 & 0.675 & 1.025 \\
BN-HBP38/CE & 1.270 & 0.826 & 1.050
\end{tabular}



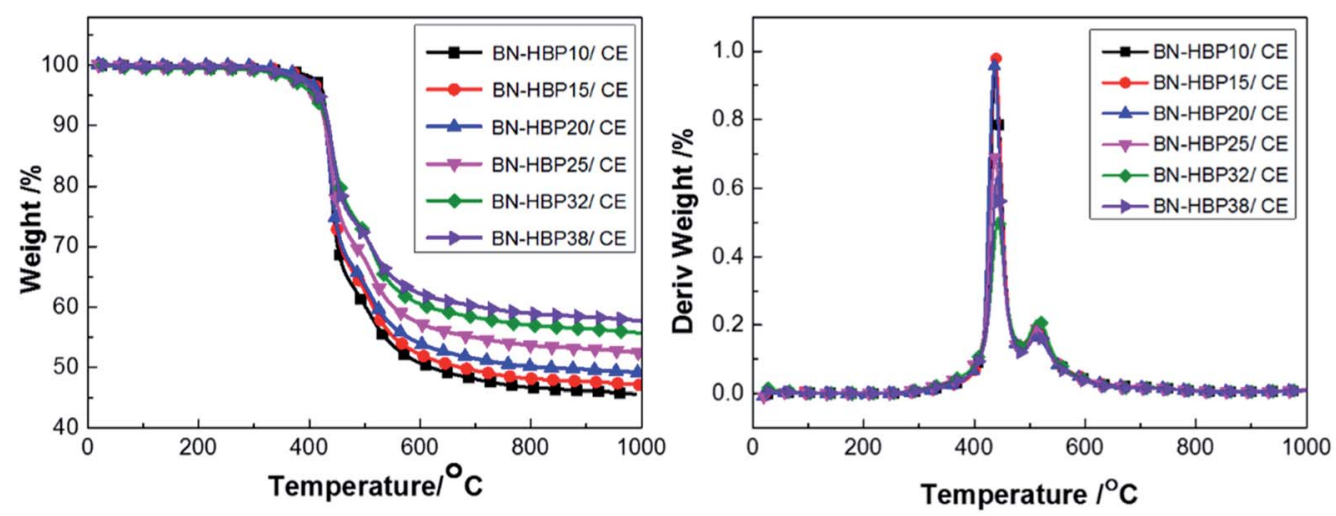

Fig. 10 TG curves of BN-HBP/CE composites with various ratios.

CE resin, BN-HBP10/CE, BN-HBP20/CE, and BN-HBP32/CE are $421{ }^{\circ} \mathrm{C}, 426^{\circ} \mathrm{C}, 419^{\circ} \mathrm{C}$, and $407^{\circ} \mathrm{C}$, respectively.

When the BN-HBP loading is low $(10 \%)$, the thermal stability of the composites is improved. A small amount of BN-HBP blocks the $\mathrm{CE}$ molecular chain, which reduces the steric hindrance of $\mathrm{CE}$ in the late polymerization and promotes $\mathrm{CE}$ crosslinking. An increase in crosslink density hinders internal thermal motion, which increases $\operatorname{Td}_{5}$. When the content continues to increase, introduction of BN-HBP destroys the crosslinked structure of the $\mathrm{CE}$, thus increasing the distance between cross-linking points and reducing crosslink density; this leads to a decreased $\mathrm{Td}_{5}$.

(5) Dynamic mechanical properties. DMA of BN-HBP/CE composites were carried out to study the mechanical properties of BN-filled composites and the effect of surface functionalization on the composites.

Fig. 11(a) shows the effect of BN-HBP content on the storage modulus $\left(E^{\prime}\right)$ of the BN-HBP/CE composites across a temperature range. The $E^{\prime}$ of all $\mathrm{BN}-\mathrm{HBP} / \mathrm{CE}$ composites in the glass state is higher than that of the neat CE resin, and the $E^{\prime}$ is observed to increase with increasing BN-HBP content. This can be attributed to the BN-HBP fillers which have a high storage modulus and limit the movement of $\mathrm{CE}$ molecules in the composites. ${ }^{47}$ In addition, the physical entanglement and chemical reaction between the surface of the BN-HBP particles and the CE molecular chain improves the interfacial adhesion, further restricts the movement of polymer chains, and thus further increases the storage modulus of $\mathrm{BN}-\mathrm{HBP} / \mathrm{CE}$ composites.

Herein, the glass transition temperature $\left(T_{\mathrm{g}}\right)$ of BN-HBP/CE composites is defined as the peak temperature of the $\tan \delta$ temperature plot shown in Fig. 11(b). The $T_{\mathrm{g}}$ of neat $\mathrm{CE}$ resin is $278^{\circ} \mathrm{C}$, and that of the BN-HBP/CE composites decreases with increasing content of BN-HBP fillers. However, when the content of BN-HBP fillers exceeds $20 \%$, the $T_{g}$ of BN-HBP/CE composites do not decrease but increase slightly. As known, the $T_{\mathrm{g}}$ of composites is closely related to the crosslink density of the resin, ${ }^{48}$ and is reduced with decreasing cross-linking density. ${ }^{37,49,50}$ For BN-HBP/CE composites, as described above, introduction of BN-HBP particles hinders the curing reaction of the CE resin and reduces the cross-linking density. Thus the $T_{\mathrm{g}}$ of BN-HBP/CE composites decreased with increasing BN-HBP content. However, we found that $T_{\mathrm{g}}$ decreases when the content of BN-HBP exceeds $32 \%$. This is attributed to an increase in particle-particle interaction caused by reduction of the distance between adjacent particles. ${ }^{47}$

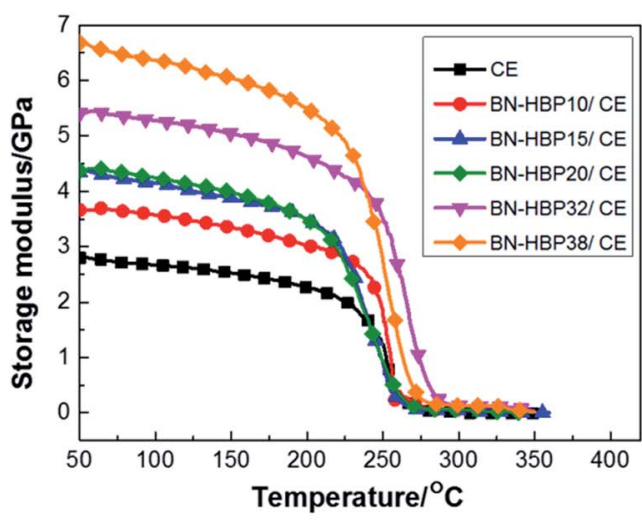

(a) storage modulus with temperature

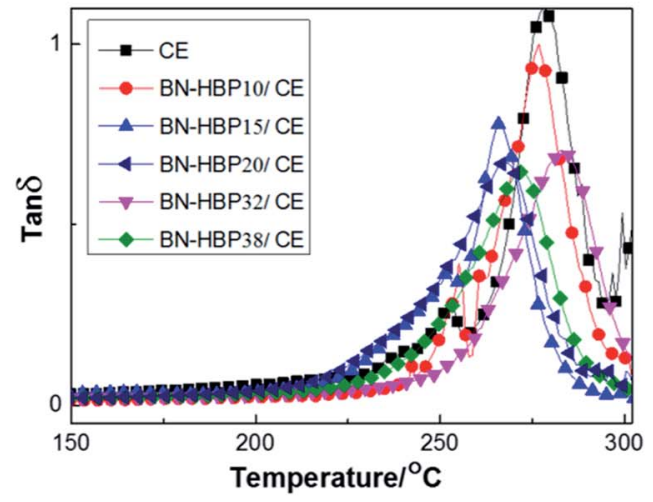

(b) $\tan \delta$ with temperature

Fig. 11 DMA curves for BN-HBP/CE composites with various fillers (a) storage modulus with temperature (b) tan $\delta$ with temperature. 


\section{Conclusions}

This study provides new insights into BN surface modification. The project was undertaken to design surface functionalized $\mathrm{BN}$, evaluate its influence on the dielectric properties and thermal conductivity of the resultant composites. The results of this investigation show that successful grafting of BN surface rigid polymers optimizes the heat transfer process, and reduces the interfacial polarization and thermal resistance. In addition, $\mathrm{BN}-\mathrm{HBP} / \mathrm{CE}$ composites are shown to possess a lower dielectric constant and lower dielectric loss. The synthesized BN-HBP32/ CE composites exhibits a dielectric constant of 3.29 at $1 \mathrm{MHz}$, a desirable $\lambda$ of $0.97 \mathrm{~W} /(\mathrm{m} \cdot \mathrm{K})$ with $\mathrm{Td}_{5}$ of $407^{\circ} \mathrm{C}$ as well as the highest $T_{\mathrm{g}}$ of $283^{\circ} \mathrm{C}$. When the loading is $38 \mathrm{wt} \%$, the $\lambda$ of $\mathrm{BN}$ $\mathrm{HBP} / \mathrm{CE}$ composites is $1.27 \mathrm{~W} /(\mathrm{m} \cdot \mathrm{K})$ Furthermore, BN surface modification greatly improves the dimensional stability of composites. BN-HBP32/CE composites possess a low shrinkage of $-0.64 \%$. An issue that was not addressed in this study is the evaluation of the grafting rate of the polymer on the BN surface. In addition, further studies need to be carried out in order to determine the type of chemical bond formed on the surface of BN-HBP with CE.

\section{Conflicts of interest}

There are no conflicts to declare.

\section{Acknowledgements}

This work is supported by Key Laboratory of Specially Functional Polymeric Materials and Related Technology of Ministry of Education, East China University of Science \& Technology, and supported by the Fundamental Research Funds for the Central Universities (50321041918013, 50321041917001).

\section{Notes and references}

1 J. M. Hutchinson, F. Roman, P. Cortes and Y. Calventus, Polimery, 2017, 62, 560-566.

2 K. C. Yung and H. Liem, J. Appl. Polym. Sci., 2007, 106, 35873591.

3 W. Ling, A. Gu, G. Liang and L. Yuan, Polym. Compos., 2010, 31, 307-313.

4 X. Huang, P. Peng, W. Peng, j. Yu, f. Liu and P. Jiang, International Conference on Condition Monitoring \& Diagnosis, 2010, vol. 31, pp. 307-313.

5 Y. Ohki, IEEE Electr. Insul. Mag., 2010, 26, 48-49.

6 H. Wu, A. Gu, G. Liang and L. Yuan, J. Mater. Chem., 2011, 21, 14838-14848.

7 W. Yuan, W. Li, Y. Mu and M. B. Chan-Park, ACS Appl. Mater. Interfaces, 2011, 3, 1702-1712.

8 K. Liang, G. Li and T. Hossien, Chem. Mater., 2006, 18, 301312.

9 F. Chao, G. Liang, W. Kong and X. Zhang, Mater. Chem. Phys., 2008, 108, 306-311.

10 T. J. Wooster, S. Abrol, J. M. Hey and D. R. MacFarlane, Composites, Part A, 2004, 35, 75-82.
11 A. Rybak and K. Gaska, J. Mater. Sci., 2015, 50, 7779-7789.

12 J. Hou, G. Li, N. Yang, L. Qin, M. E. Grami, Q. Zhang, N. Wang and X. Qu, RSC Adv., 2014, 4, 44282-44290.

13 M. T. Huang and H. Ishida, J. Polym. Sci., Part B: Polym. Phys., 1999, 37, 2360-2372.

14 S. Kemaloglu, G. Ozkoc and A. Aytac, Thermochim. Acta, 2010, 499, 40-47.

15 K. Kim, M. Kim, Y. Hwang and J. Kim, Ceram. Int., 2014, 40, 2047-2056.

16 R. J. Warzoha and A. S. Fleischer, Nano Energy, 2014, 6, 137158.

17 N. Tsutsumi, N. Takeuchi and T. Kiyotsukuri, J. Polym. Sci., Part A: Polym. Chem., 1991, 29, 1085-1093.

18 H. L. Lee, O. H. Kwon, S. M. Ha, B. G. Kim, Y. S. Kim, J. C. Won, J. Kim, J. H. Choi and Y. Yoo, Phys. Chem. Chem. Phys., 2014, 16, 20041-20046.

19 H. Wu and M. R. Kessler, ACS Appl. Mater. Interfaces, 2015, 7, 5915-5926.

20 B. I. Voit and A. Lederer, Chem. Rev., 2010, 41, 5924-5973.

21 C. Wu, X. Huang, G. Wang, X. Wu, K. Yang, S. Li and P. Jiang, J. Mater. Chem., 2012, 22, 7010-7019.

22 H. Zhang, Y. Dong, L. Wang, G. Wang, J. Wu, Y. Zheng, H. Yang and S. Zhu, J. Mater. Chem., 2011, 21, 13530-13537.

23 L. Gao and J. Li, J. Am. Ceram. Soc., 2003, 86, 1982-1984.

24 M. Labet, W. Thielemans and A. Dufresne, Biomacromolecules, 2007, 8, 2916-2927.

25 F. Milanesi, G. Cappelletti and R. Annunziata, J. Phys. Chem. C, 2010, 114, 8287-8293.

26 L. An, Y. Pan, X. Shen, H. Lu and Y. Yang, J. Mater. Chem., 2008, 18, 4928-4941.

27 S. Y. Kim, J. Park, H. C. Choi, J. P. Ahn, J. Q. Hou and H. S. Kang, J. Am. Chem. Soc., 2007, 129, 1705-1716.

28 T. Sainsbury, T. Ikuno, D. Okawa and D. Pacilé, J. Phys. Chem. C, 2007, 111, 341-357.

29 Y. S. Lipatov, E. G. Moisya and G. M. Semenovich, Polymer, 1975, 16, 582-584.

30 Z. Petrović and N. Stojaković, Polym. Compos., 1988, 9, 42-50.

31 Y. Zhang and C. Jia, Ceram. Int., 2019, 45, 6491-6498.

32 W. Zhou, P. Xiao, Y. Li and L. Zhou, Ceram. Int., 2013, 39, 6569-6576.

33 J. Gu, S. Xu, Q. Zhuang, Y. Tang and J. Kong, IEEE Trans. Dielectr. Electr. Insul., 2017, 24, 784-790.

34 J. P. Adohi, C. Guillermin and P. Rain, Conference on Electrical Insulation \& Dielectric Phenomena, IEEE, 2004, pp. 158-161.

35 Y. Lei, Z. Han, D. Ren, H. Pan, M. Xu and X. Liu, Macromol. Res., 2018, 26, 602-608.

36 J. P. Eloundou, Eur. Polym. J., 2002, 38, 431-438.

37 Y. Gao, A. Gu, Y. Jiao, Y. Yang, G. Liang, J.-t. Hu, W. Yao and L. Yuan, Polym. Adv. Technol., 2012, 23, 919-928.

38 W. Yu, H. Xie and D. Bao, Nanotechnology, 2010, 21, 055705.

39 Y. Guo and S. N. Leung, Mater. Chem. Phys., 2018, 214, 221228.

40 G.-W. Lee, M. Park, J. Kim, J. I. Lee and H. G. Yoon, Composites, Part A, 2006, 37, 727-734.

41 D. P. H. Hasselman and L. F. Johnson, J. Compos. Mater., 1987, 21, 508-515. 
42 L. Zhai, Z. Liu, C. Li, X. Qu, Q. Zhang, G. Li, X. Zhang and B. Abdel-Magid, RSC Adv., 2019, 9, 5722-5730.

43 W. Cui, F. Du, J. Zhao, W. Zhang, Y. Yang, X. Xie and Y.-W. Mai, Carbon, 2011, 49, 495-500.

44 W. Zhou, S. Qi, Q. An, H. Zhao and N. Liu, Mater. Res. Bull., 2007, 42, 1863-1873.

45 T. H. Chiang and T. E. Hsieh, J. Inorg. Organomet. Polym. Mater., 2006, 16, 175-183.

46 A. Patti, P. Russo, D. Acierno and S. Acierno, Composites, Part $B, 2016,94,350-359$.
47 S. Kwon, T. Adachi, W. Araki and A. Yamaji, Acta Mater., 2006, 54, 3369-3374.

48 N. Tagami, M. Hyuga, Y. Ohki, T. Tanaka, T. Imai, M. Harada and M. Ochi, IEEE Trans. Dielectr. Electr. Insul., 2010, 17(7), 214-220.

49 W. K. Goertzen and M. R. Kessler, Composites, Part A, 2008, 39, 761-768.

50 A. Permal, M. Devarajan, L. H. Huong, T. Zahner, D. Lacey and K. Ibrahim, Polym. Compos., 2018, 39, E1372-E1380. 